\title{
Samsun Bölgesi için Güneş Radyasyonunun Yapay Sinir Ağı ile Tahmini
}

\author{
Sema Ariman ${ }^{1 *}$, Gaye Yeşim Taflan ${ }^{2}$, Esra Çelik $^{3}$ \\ ${ }^{1 * S a m s u n ~ U ̈ n i v e r s i t e s i, ~ H a v a c ı l ı k ~ v e ~ U z a y ~ B i l i m l e r i ~ F a k u ̈ l t e s i, ~ M e t e o r o l o j i ~ M u ̈ h e n d i s l i g ̆ i ~ B o ̈ l u ̈ m u ̈, ~ S a m s u n, ~ T u ̈ r k i y e, ~(O R C I D: ~ 0000-0001-7201-9243), ~}$ \\ sema.ariman@samsun.edu.tr \\ ${ }^{2}$ Samsun Üniversitesi, Havacılık ve Uzay Bilimleri Fakültesi, Uçak Bakım ve Onarım Bölümü, Samsun, Türkiye, (ORCID: 0000-0003-3022-8551), \\ gaye.taflan@samsun.edu.tr \\ ${ }^{3}$ Muş Meteoroloji İstasyon Müdürlüğü, Muş, Türkiye, (ORCID: 0000-0003-4819-1945), esracelik@mgm.gov.tr
}

(İlk Geliş Tarihi 21 Ocak 2021 ve Kabul Tarihi 24 Temmuz 2021)

(DOI: $10.31590 /$ ejosat.866139)

ATIF/REFERENCE: Arıman, S., Taflan, G. Y. \& Çelik, E. (2021). Samsun Bölgesi için Güneş Radyasyonunun Yapay Sinir Ağı İle Tahmini. Avrupa Bilim ve Teknoloji Dergisi (25), 680-687.

\section{$\ddot{O} \mathbf{z}$}

Yenilenebilir enerji kaynaklarından güneş enerji sistemlerinin tasarımında güneş radyasyonunu tahmin etmek oldukça önemlidir. Güneş enerjisi, global güneş radyasyonuna bağlıdır. Güneş radyasyonunun Yapay Sinir ağı modeli (YSA) ile tahmin edilmesinde girdi değişkeni olarak, hava sıcaklığı, güneşlenme süresi, buhar basıncı, bulutluluk gibi çeşitli meteorolojik değişkenler kullanılmaktadır. Bu çalışmada, Samsun bölgesi için Mart 2017-Şubat 2019 tarihleri arasındaki günlük güneş radyasyonu YSA yöntemi ile tahmin edilmeye çalışılmıştır. YSA yönteminde farklı giriş değişkenleri için Levenberg-Marquardt eğitim algoritması, logaritmik sigmoid ve doğrusal transfer fonksiyonu kullanılmıştır. Model performansı en yüksek 9 girişli meterolojik veriler (ortalama sıcaklık, ortalama nispi nem, ortalama rüzgar hızı, ortalama buhar basıncı, ortalama bulutluluk oranı, güneşlenme süresi, maksimum sıcaklık, minimum sıcaklık, 5 cm'de toprak sıcaklığı) ile elde edilmiştir. Test verileri için R değeri 0.9603, MSE değeri 0.3516 olarak bulunmuştur. İleri beslemeli YSA modeli yaklaşımının diğer meteorolojik değişkenler ile birlikte güneş radyasyonunu tahmin etmek için yüksek bir performans sağladığı görülmüştür. Ayrıca, YSA’ya güneşlenme süresi giriş olarak verildiğinde, R değeri 0.9032 olarak elde edilmiştir.

Anahtar Kelimeler: Güneş radyasyonu, Meteorolojik değişkenler, İleri beslemeli yapay sinir ağı, Levenberg-Marquardt

\section{Prediction of Solar Radiation with} \section{Artificial Neural Network for Samsun Region}

\begin{abstract}
It is very important to predict solar radiation in the design of solar energy systems from renewable energy sources. Solar energy depends on global solar radiation. Various meteorological variables such as air temperature, sunshine duration, vapor pressure, cloudiness are used as input variables in estimating solar radiation with Artificial Neural Network Model (ANN). In this study, ANN was used to predict the daily solar radiation values of Samsun region between March 2017 and February 2019. Levenberg-Marquardt training algorithm, logarithmic sigmoid and linear transfer function were used for different input parameters in ANN method. The best model performance was obtained with 9-input meteorological data (average temperature, average wind speed, average vapor pressure, average cloudiness rate, sunshine duration, maximum temperature, minimum temperature, soil temperature at $5 \mathrm{~cm}$ ). The correlation coefficient (R) for the test data was 0.9603 and the mean square error (MSE) was 0.3516 . It has been observed that the feed forward ANN model provides a high performance for predicting solar radiation along with other meteorological parameters. In addition, when the sunshine duration was given as input to the ANN, R value was obtained as 0.9032 .
\end{abstract}

Keywords: Solar radiation, Meteorological variables, Feed-Forward neural network, Levenberg-Marquardt

\footnotetext{
* Sorumlu Yazar: Samsun Üniversitesi, Havacıllk ve Uzay Bilimleri Fakültesi,Meteoroloji Mühendisliği Bölümü, Samsun, Türkiye, ORCID: 00000001-7201-9243, sema.ariman@samsun.edu.tr
} 


\section{Giriş}

Enerji, insanların ihtiyaçlarını karşılamak için kaynakların işlenmesinde her zaman önemli bir rol oynamıştır. Küresel toplam enerji tüketimi, toplumun tüketim eğilimlerinin yükselmesiyle birlikte hızla artmaktadır. Ekonomiler daha fazla sanayileşmeye bağlı olarak büyümektedir. Dünyanın enerji tüketimi son 40 yılda ikiye katlanmıştır. Sektörler, 2016'da 9,6 Gt olan toplam nihai enerji tüketiminin\% 37'sini tüketmiştir (IEA, 2018a). Mevcut enerji sistemleri genellikle yenilenemeyen, dünya çapında dağıtılan ve teslimatı kritik olarak sürdürülemez olan fosil yakıtların yanmasına dayanmaktadır (Koçak ve ark., 2020). Dünyanın geleceğini tehdit eden küresel isınmaya neden olan karbon emisyonlarının çoğu fosil yakıtların yakılmasıyla üretilmektedir. Yakıtların yanmasından kaynaklanan $\mathrm{CO}_{2}$ emisyonları 2016 yılında 32,3 Gt'dir. $\mathrm{Bu} \mathrm{CO}_{2}$ emisyonlarının \% 19'undan sanayi sektörü sorumludur (IEA, 2018a, 2018b). 130 ülkenin katılımıyla imzalanan Paris anlaşmasına göre, yüksek seviyelerde $\mathrm{CO}_{2}$ emisyonları küresel ssınmanın ise ana nedenidir (Gibb ve ark., 2018).

Enerji üretimi, sera gazı emisyonlarının büyük bir kısmından sorumludur ve Küresel İ̉klim Değişikliği'nin önde gelen nedeni ise antropojenik etkilerdir (Oreskes, 2004; IPCC 2007). Bu nedenle, sera gazı emisyonlarının azaltılması için yenilebilir enerji kaynaklarına ihtiyaç bulunmaktadır (Lee ve Choi, 2019). Sera gazı emisyonlarının azaltılması yenilenebilir enerji kaynaklarının dünyanın her yerinde kullanılmasıyla olur. Yenilenebilir enerjinin dünya enerji arzındaki payı sürekli artmakla birlikte yalnızca \% 4,2 civarındadır (Koçak ve ark., 2020).

Güneş enerjisi potansiyeli, doğal enerji kaynakları arasında en büyüğüdür. Güneş enerjisi, güneşin yaydığı termal radyasyondan elde edilir. Güneş enerjisi, yılda yaklaşık 157549.837 EJ üreten bol bir kaynaktır (Alva ve ark., 2018). Dünyadaki diğer yenilenebilir enerji kaynakları ve fosil yakıtlar da dahil olmak üzere diğer tüm enerji kaynakların nihai kaynağıdır. Dünyaya düşen güneş enerjisi, toplam küresel enerji arzının 13.800 Mtoe'den çok daha fazladır. Güneş, $\mathrm{CO}_{2}$ emisyonlarını azaltan enerji açısından verimli çözümler sağlayacak sınırsız ve temiz bir kaynaktır (Atkins ve ark., 2010). Birleşmiş Milletler'in Çevre Programı (UNEP) 2015 raporuna göre, konuma bağlı olarak 1,4 MWth $\left(2000 \mathrm{~m}^{2}\right)$ güneş enerjisi sisteminin her biri yaklaşı 175 metrik ton $\mathrm{CO}_{2}$ emisyonu tasarrufu sağlayabilir (UNEP 2015). Yeryüzünün x-1şınları, UV1şınları, kızılötesi 1şınlar şeklinde aldığı Güneş Radyasyonu verileri, yeryüzünde güneşten alınan enerji miktarı hakkında bilgi verdiği için önemli ve faydalı bir veridir. Teknolojinin gelişmesiyle birlikte enerji talepleri her geçen gün hızla artarken, bu yenilenebilir ve sürdürülebilir enerji kaynağının tahmin ve öngörme ihtiyacını da artırmaktadır.

Yapay Sinir A $\breve{1}$ (YSA), insan beyninin performansına benzer bir şekilde öğrenen ve performans gösteren, beyinden ilham alan yapay zeka tekniklerinin bir alt kümesidir (Strobl ve Forte 2007; Amanollah ve ark., 2017; Oğuz ve Pekin, 2019; Özcan ve Köprü, 2020). YSA'daki farklı nöronlar arasındaki ara bağlantı modeline ağ mimarisi denir. Çok katmanlı algılayıcı (MLP) ağı, YSA'nın en yaygın ve pratik mimarilerinden biridir. MLP'de, her nöron, farklı nöron girdilerinin diğer nöronlara olan göreceli etkisini temsil eden değişen ağırlıklarla, komşularına bağlıdır (Moghadassi ve ark., 2009) Girişlerin ağırlıklı toplamı, bir aktivasyon fonksiyonu kullanılarak gizli nöronlara iletilir. Gizli nöronların çıktıları, başka bir dönüşüme uğradığı çıkış nöronuna girdi olur(Heidari ve ark., 2016).YSA'nın öğrenme, genelleme, hataları tolare etme gibi yeteneklerinden dolayı lineer olan ve lineer olmayan sistemlerin modellemesinde oldukça geniş uygulama alanları mevcuttur (Atik ve Deniz, 2007). Şahan ve Okur (2016) çalışmasında Akdeniz Bölgesinden seçilen on dört yerleşkede aylık ortalama toplam güneş 1şınım şiddetini tahmin etmek amacıyla YSA modeli kullanmıştır. YSA modelinde 1993-2010 yılları arasındaki meteorolojik ve coğrafik verileri (aylık ortalama güneş radyasyonu, ortalama hava sıcaklığı, minimum toprak üstü sıcaklığı, $5 \mathrm{~cm}$ 'deki toprak sıcaklığı, bağıl nem, bulutluluk, hava basınc1, güneşlenme süresi, istasyon, ay, enlem, boylam ve yükseklik) kullanmıştır. Model performans kriterleri; $\mathrm{R}^{2} 0.94$, MSE 1.072 'dir. Sonuçlar, tahmin edilen ve ölçülen toplam güneş ışınım şiddetinin değerlerinin oldukça başarılı olduğunu göstermiştir. Kumar ve ark., (2013) Kuzey Hindistan'ın belirlenen bölgelerdeki tepelik alanların sadece enlem ve boylamlarını göz önünde bulundurarak dört farklı istasyon verisi kullanılarak aylık ortalama toplam güneş radyasyonu (1şınım) verileri kullanılarak sinir ağı uyumlu araçlarla analiz etmişlerdir. Sinir ağı modelinde 10 nöron kullanmışlardır. YSA modelinde, determinasyon katsayısını $R^{2} 0.99$ elde etmişlerdir.

Yenilenebilir enerji kaynaklarından güneş enerji sistemlerinin tasarımında güneş radyasyonunu tahmin etmek oldukça önemlidir. Güneş enerjisi, global güneş radyasyonuna bağlıdır. Güneş radyasyonu, hava sıcaklığı, güneşlenme süresi, bağıl nem, bulutluluk gibi çeşitli meteorolojik değişkenler ile Yapay Sinir ağı modeli ile tahmin edilebilmektedir. Böylece, sinir ağlarının güneş radyasyonu miktarını tahmin etme kapasitesi değerlendirilir ve en az hatayı elde etmek için ağ mimarileri geliştirilir (Behrang ve ark., 2010; Azadeh ve ark., 2009; Bojanowski ve ark., 2013; Bayat ve Mirlatifi, 2009). Bu çalışmada Samsun bölgesi için güneş radyasyonu, ileri beslemeli yapay sinir ağı yöntemi (MLP) ile tahmin edilmiştir.

\section{Materyal ve Metot}

\section{1. Çalışma Alanı}

Samsun ili; Karadeniz sahil şeridinde Yeşilırmak ve Kızılırmak nehirlerinin Karadeniz'e döküldükleri deltalar arasında yer almaktadır (Şekil 1) ve 9579 km² $^{2}$ lik yüz ölçümüne sahiptir. Coğrafi konum olarak, $40^{\circ} 50^{\prime}-41^{\circ} 51^{\prime}$ kuzey enlemi ile $37^{\circ} 08^{\prime}$ ve $34^{\circ} 25^{\prime}$ doğu boylamları arasında yer almaktadır (Dengiz ve Sarığlu, 2011). Dağlık alanlar, dağlık alanlar üzerinde gelişmiş aşınım yüzeyleri, dağlı alanlar arasındaki depresyonlar ile delta ovaları Samsun ili yeryüzü şekillerinin ana unsurlarını oluştururlar.

Genellikle 1lıman bir özelliğe sahip olan Samsun iklimi sahil şeridi ve iç kesimlerde ayrı özellik gösterir. Sahil şeridinde; yazların sıcak, kışların ılık ve yağışlı geçtiği Karadeniz ikliminin özellikleri görülür. Yıllık ortalama sıcaklık sahil kesimlerde alanı bulunan Bafra, Çarşamba, Terme ve Tekkeköy ilçelerinde 14$15^{\circ} \mathrm{C}$ arasında iken; Havza, Lâdik ve Vezirköprü ilçelerinin yüksek dağ kesimlerinde $5^{\circ} \mathrm{C}$ düzeylerine kadar indiğinden iç kesimler Akdağ ve Canik Dağları'nın etkisinde kalır. Bu sebeple kışlar soğuk ve kar yağışlı, yazları ise serin geçmektedir. Samsun'un doğu kıyısında yer alan Çarşamba, Terme ve Tekkeköy ilçesinin bir kısmı 900-1000 mm yağış alırken, batı sahillerinde yer alan Bafra ilçesi 800 ile $900 \mathrm{~mm}$ arasında, orta 
kesimlerde ise $700 \mathrm{~mm}$ civarında ortalama yağış almaktadır. Kuzey kesimlerde yer alan Vezirköprü ve Havza ilçeleri özellikle

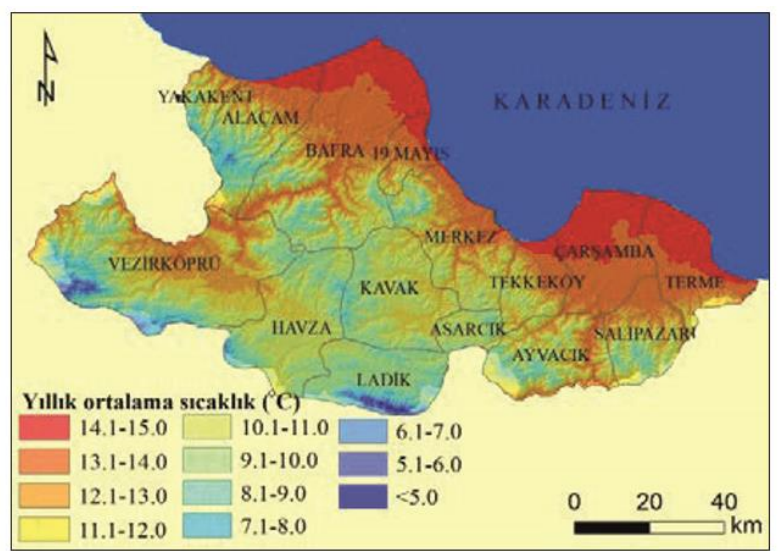

Canik Dağları'nın etkisiyle yağıș miktarının 500-600 mm'ye kadar azaldığı görülmektedir (Turan ve ark., 2018).

Şekil 1. Samsun iline ait sıcaklık ve yağış dă̆llım haritaları (Turan ve ark., 2018)

\subsection{Verilerin Toplanması}

Samsun ilinin günlük güneş radyasyon değerinin tahmin edilmesi için YSA yöntemi kullanılmıştır. Güneş radyasyonunun YSA modeli kullanılarak tahmin edilmesi için Mart 2017- Şubat 2019 tarihleri arasında, iki farklı istasyona (Tablo 1) ait günlük meteorolojik veriler kullanılmıştır. $\mathrm{Bu}$ meteorolojik veriler; günlük ortalama sıcaklık $\left({ }^{\circ} \mathrm{C}\right)$, günlük ortalama nispi nem(\%), günlük ortalama rüzgar hızı $(\mathrm{m} / \mathrm{s})$, günlük ortalama buhar basıncı $(\mathrm{hPa})$, günlük ortalama bulutluluk oranı, güneşlenme süresi

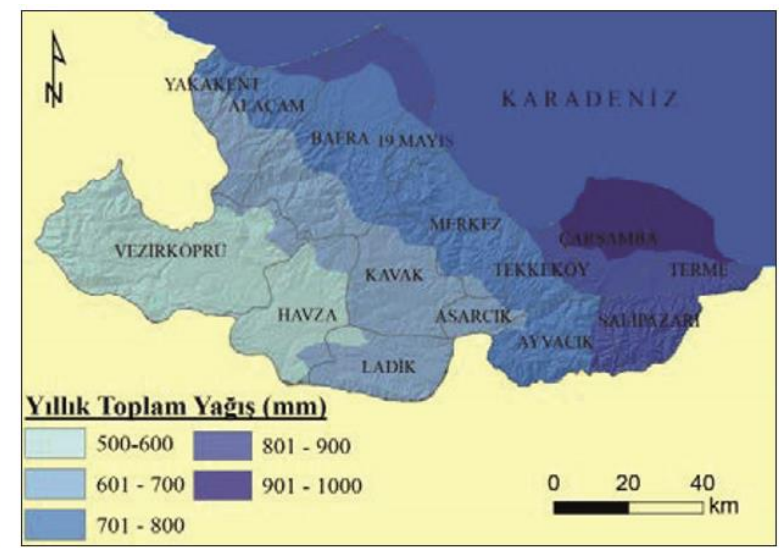

Tablo 1. Meteorolojik istasyonların konum ve özellikleri

\begin{tabular}{lcccc}
\hline \multicolumn{1}{c}{ İstasyon Adı } & İstasyon No & Enlem & Boylam & Yükseklik (m) \\
\hline Bafra Toprak Su Araştırma & 18133 & 41,6017 & 35,9189 & 15 \\
Tekkeköy Karadeniz Tagem & 18132 & 41,2303 & 36,4986 & 6 \\
\hline
\end{tabular}

\subsection{Yapay Sinir Ăğ Yöntemi}

YSA modeli; girdi katmanı, gizli katman ve çıktı katmanı olmak üzere üç katmandan oluşmaktadır. Girdi katmanı, ağa giriş olarak değişkenlerin verildiği katmandır ve girdi katmanındaki nöron sayısı kullanılan değiş̧en sayısına eşittir. Gizli katman, girdi katmanı ile çıktı katmanı arasında yer alır. Gizli katman sayısı uygulamaya göre değişmektedir. Çıktı katmanı, ağın üretmesi istenen çıkış değerlerinin elde edildiği katmandır ve çıktı katmanındaki nöron sayısı, ağın üretmesi istenen değişkenin/değişkenlerin sayısına eşittir. $\mathrm{Bu}$ yapının oluşturulmasında kullanılan ilke, verilerin ağırlıklarla çarpılıp transfer fonksiyonunun ve ardından aktivasyon fonksiyonunun uygulanmasıdır. Uygulamada farklı transfer fonksiyonları kullanılmaktadır. Bu çalışmada toplama fonksiyonu kullanılarak, yapay sinir ağı modellemesi ile Samsun bölgesindeki güneş radyasyonu değerleri tahmin edilmiş, modelin tahmin tutarlılığı araştırılmıştır. Model girişi için farklı meteorolojik değişken kombinasyonları oluşturularak güneş radyasyonunun en doğru şekilde tahmin edilmesi amaçlanmıştır. (saat), günlük maksimum sıcaklık $\left({ }^{\circ} \mathrm{C}\right)$, günlük minimum sıcaklık $\left({ }^{\circ} \mathrm{C}\right), 5 \mathrm{~cm}$ 'de toprak sıcaklığı $\left({ }^{\circ} \mathrm{C}\right)$, günlük toplam küresel güneş radyasyonu (kWsaat $\left./ \mathrm{m}^{2}\right)$ Meteoroloji Genel Müdürlüğ̈̈’nden temin edilmiştir. Güneş radyasyonunu tahmin etmek için meteorolojik veriler yapay sinir ağında eğitim, doğrulama (validasyon) ve test için sırasıyla $\% 70, \% 15$ ve $\% 15$ oranında rasgele olarak ayrılmıştır. Verilerin rasgele ayrıştırılmasından önce, meteorolojik verilerin herhangi birinin eksik olduğu güne ait veriler çıkarılarak ağın tahminleme işleminde kullanılmamıştır. 


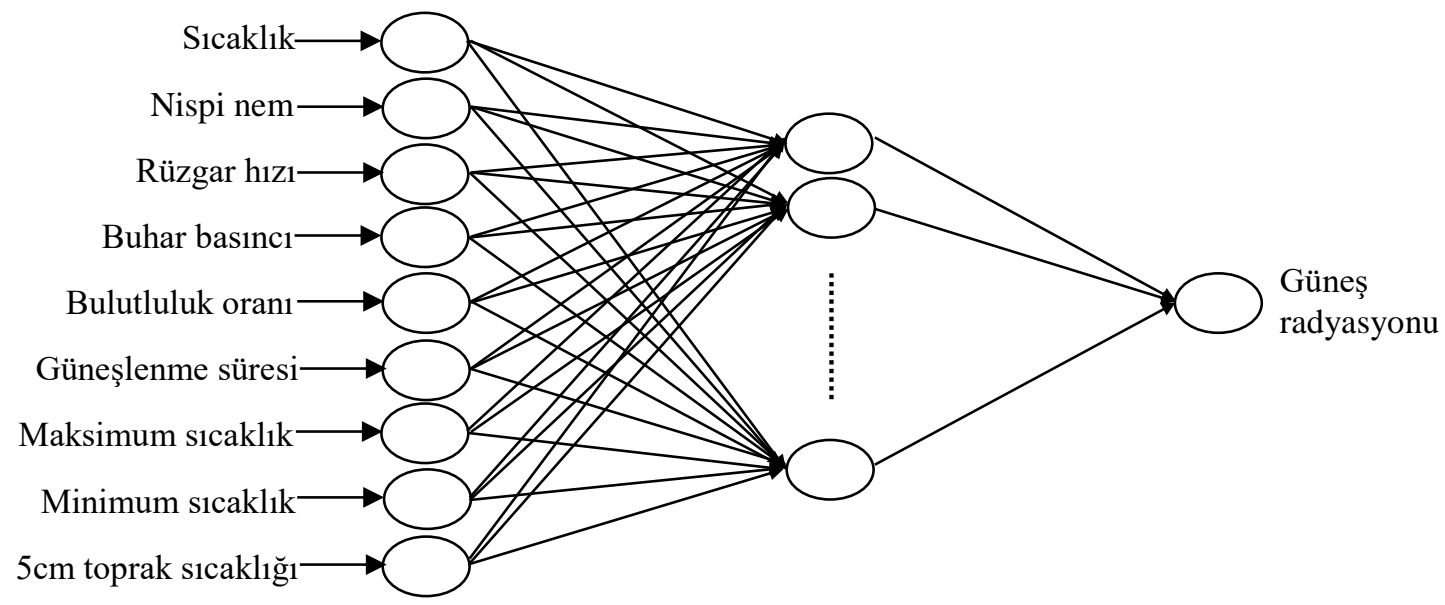

Girdi katmanı Gizli katman $\quad$ Çıkış katmanı

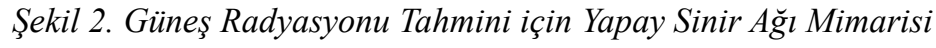

Eğitim algoritması olarak Levenberg-Marquardt kullanılmıștır. Aktivasyon fonksiyonu olarak gizli katmanda logaritmik sigmoid (logsig) transfer fonksiyonu, çıtı katmanında ise doğrusal (purelin) transfer fonksiyonu kullanılmıştır. Aynı eğitim, doğrulama ve test verileri için Nöron sayıları 1-20 aralığında değiştirilerek yöntemin başarımı incelenmiştir.

$\mathrm{Bu}$ çalışmada, farklı girdi kombinasyonları oluşturularak en az meteorolojik değişken(ler) ile en iyi güneş radyasyonu tahmini edebilecek değişkenler belirlenmeye çalışılmıştır. Kombinasyonların nasıl yapılacağına karar verebilmek için meteorolojik değişkenlerin güneşlenme radyasyonu ile korelasyonlarına bakılmıştır. $\mathrm{Bu}$ sonuçlara göre günlük güneşlenme süresi en büyük $(\mathrm{R}=0.874)$, nispi nem $(\mathrm{R}=0.0501)$ en küçük mutlak korelasyon değerine sahiptir.

YSA model yaklaşımında Güneş radyasyonun, diğer meteorolojik değişkenlerle korelasyonu belirlenmiş ve buna göre en düşük korelasyona sahip nispi nem değişkeni çıkarılmaya başlanarak değişken sayısı azaltılmaya çalışılmıştır (Tablo 2). YSA modelinde eğitim, doğrulama ve test için giriş değişkeni; ortalama sicaklık $(\mathrm{S})$, ortalama nispi nem $(\mathrm{NN})$, ortalama rüzgar hızı (RH), ortalama buhar basıncı (BB), ortalama bulutluluk oranı (BO), güneşlenme süresi (GS), maksimum sıcaklık (EYS), minimum sicaklık (EDS), 5 cm'de toprak sicaklığı (TS) kullanılmış ve modelin performans kriterleri değeri, MSE değerleri belirlenmiştir.

\subsubsection{YSA Modelinin İstatistiksel Performans Kriterleri}

Tüm modellerin sonuçları ortalama karesel hata (MSE) ve korelasyon katsayısı $(R)$ metriklerine göre karşılaştırılmıştır. MSE ve R performans ölçütleri Denklem 1 ve 2 de verilmiştir. Burada $x$ ve $y$ sirasıyla ölçülen ve tahmin edilen güneş radyasyonunu, $\bar{x}$ ve $\bar{y}$ ise bu değerlerin ortalamalarını göstermektedir. Bunlar, farklı YSA modellerinden elde edilen değerleri analiz etmek ve sonuçlar ile gözlemlenen değerleri karşılaştırmak için kullanılır (Changa ve ark., 2009; Amanollahi ve ark., 2017; Zhang, ve ark., 2020; Naderloo, L., 2020). Eğitim sırasında, YSA değişkenlerin uygun değerlerini bulmak için, genellikle ağ tahmininin MSE performans metriği her yinelemede en aza indirilmelidir.

$$
\begin{gathered}
M S E=\frac{1}{N} \sum(x-y)^{2} \\
R=\frac{\sum(x-\bar{x})(y-\bar{y})}{\sqrt{\sum(x-\bar{x})^{2} \sum(y-\bar{y})^{2}}}
\end{gathered}
$$

\section{Araştırma Sonuçları ve Tartışma}

\subsection{YSA Yönteminin Performansının Değerlendirilmesi}

Güneş radyasyonunu tahmin etmek için İleri beslemeli YSA modeli kullanılmıştır. Rasgele olarak ayrıştırılmış olan veriler içinden, eğitim verileri ağa sunularak ağın öğrenme işlemi gerçekleştirilmiş eğitim, doğrulama ve test verilerinin korelasyon katsayıları ve ortalama karesel hata değerleri hesaplanmıştır. Nöron sayıları 1 ile 20 aralığında değiştirilerek bu işlem tekrar edilmiş ve en yüksek korelasyon katsayısına sahip test verileri oluşturulmuştur (Tablo 3). En iyi sonuç S, NN, RH, BB, BO, GS, EYS, EDS, TS ile elde edilen 9 girişli ağ için elde edilmiştir. Burada eğitim, doğrulama ve test için R değerleri sırasıyla 0.9742 , 0.9697 ve 0.9603 olarak hesaplanmıştır. Aynı giriş değişkenleri için hata değeri ise, eğitim, doğrulama ve test için $0.2113,0.2366$ ve 0.3516 olarak hesaplanmıştır. Tüm veri için değerlendirildiğinde $\mathrm{R}=0.9712, \mathrm{MSE}=0.2362$ elde edilmiştir. Denormalize yapıldıktan sonra ağın ürettiği değerlerin yer aldığ saçılma diyagramı Şekil 3'te verilmiştir. YSA'ya sadece güneşlenme süresi giriş olarak verildiğinde eğitim, doğrulama ve test için $\mathrm{R}$ değerleri sirasıyla $0.8813,0.887$ ve 0.9032 olarak hesaplanmıştır. Tüm veriler için hesaplanan $\mathrm{R}$ ve MSE değerleri $\mathrm{R}=0.8854$, $\mathrm{MSE}=0.9044^{\prime}$ tür. 
Tablo 2. Meteorolojik değişkenlenlerin korelasyon analizi

\begin{tabular}{c|llllllllll}
\hline & \multicolumn{1}{|c}{ S } & NN & RH & BB & BO & GS & EYS & EDS & TS & GR \\
\hline S & 1 & & & & & & & & & \\
NN & -0.0234 & 1 & & & & & & & & \\
RH & -0.1683 & -0.3141 & 1 & & & & & & & \\
BB & 0.9358 & 0.2732 & -0.2129 & 1 & & & & & & \\
BO & -0.1673 & 0.1716 & -0.0114 & -0.0901 & 1 & & & & & \\
GS & 0.3363 & -0.0823 & -0.0311 & 0.2836 & -0.7287 & 1 & & & & \\
EYS & 0.9365 & -0.0629 & -0.2192 & 0.8412 & -0.3514 & 0.4716 & 1 & & & \\
EDS & 0.9553 & 0.0526 & -0.1231 & 0.9337 & 0.0389 & 0.1607 & 0.8114 & 1 & & \\
TS & 0.9543 & 0.0985 & -0.2181 & 0.9445 & -0.1828 & 0.4199 & 0.8815 & 0.9208 & 1 & \\
GR & 0.536 & 0.0501 & -0.0819 & 0.516 & -0.5421 & 0.874 & 0.5983 & 0.4085 & 0.6568 & 1 \\
\hline
\end{tabular}

Tablo 3. Giriş parametrelerinin değişimine bağlı YSA model performansı

\begin{tabular}{l|cccccc}
\hline \multicolumn{1}{c|}{ Giriş Değişkenleri } & $\begin{array}{c}\mathbf{R} \\
\text { (eğitim) }\end{array}$ & $\begin{array}{c}\mathbf{R} \\
\text { (doğrulama) }\end{array}$ & $\begin{array}{c}\mathbf{R} \\
\text { (test) }\end{array}$ & $\begin{array}{c}\text { MSE } \\
\text { (eğitim) }\end{array}$ & $\begin{array}{c}\text { MSE } \\
\text { (doğrulama) }\end{array}$ & $\begin{array}{c}\text { MSE } \\
\text { (test) }\end{array}$ \\
\hline \hline S,NN,RH,BB,BO,GS,EYS,EDS,TS, & 0.9855 & 0.9743 & 0.9625 & 0.119 & 0.2091 & 0.3331 \\
GR(t-1)* & & & & & & \\
S,NN,RH,BB,BO,GS,EYS,EDS,TS & 0.9742 & 0.9697 & 0.9603 & 0.2113 & 0.2366 & 0.3516 \\
S,RH,BB,BO,GS,EYS,EDS,TS & 0.9758 & 0.967 & 0.9581 & 0.1983 & 0.2649 & 0.3703 \\
S,BB,BO,GS,EYS,EDS,TS & 0.9696 & 0.9673 & 0.9594 & 0.2512 & 0.2527 & 0.3585 \\
S,BB,BO,GS,EYS,TS & 0.9651 & 0.963 & 0.9588 & 0.2837 & 0.2881 & 0.364 \\
S,BO,GS,EYS,TS & 0.9695 & 0.9665 & 0.958 & 0.2487 & 0.2598 & 0.3702 \\
BO,GS,EYS,TS & 0.961 & 0.955 & 0.9454 & 0.3167 & 0.3497 & 0.4791 \\
GS,EYS,TS & 0.9631 & 0.9579 & 0.9437 & 0.3007 & 0.3232 & 0.4934 \\
GS,TS & 0.9478 & 0.9405 & 0.9348 & 0.4208 & 0.4556 & 0.5739 \\
GS & 0.8813 & 0.887 & 0.9032 & 0.9263 & 0.8529 & 0.8539 \\
\hline
\end{tabular}

*GR( t -1) zamanındaki güneş radyasyonu verisi YSA giriş verisi olarak dahil edilmiştir

Test verileri için ölçülen ve tahmin edilen güneș radyasyonu verilerinin rastgele seçilmiş olan günlere göre değișimi Şekil 4'te verilmiş̧ir. Güneşlenme radyasyonu için YSA model tahmini ve ölçülen değerlerinin birbirine yakın ve paternlerinin ise benzer olduğu görülmektedir.

Güneş radyasyonu tahmininde modelin başarımını incelemek için bir gün önceki güneşlenme radyasyonu $(\mathrm{GR}(\mathrm{t}-1))$ değişkeni de YSA ağına giriş olarak eklenerek (10 girişli: $\mathrm{S}, \mathrm{NN}, \mathrm{RH}, \mathrm{BB}$, $\mathrm{BO}, \mathrm{GS}$, EYS, EDS, TS, GR(t-1)) t anındaki güneşlenme radyasyonu tahmin edilmiştir. Bu model için kullanılan eğitim algoritması, aktivasyon fonksiyonları değiştirilmemiş̧tir. Nöron sayıları 1-20 aralığında değiştirilmiştir. Eğitim, doğrulama ve test verileri için korelasyon katsayıları sırasıyla $0.9855,0.9743$ ve 0.9625 olarak elde edilmiştir (Tablo 3). Aynı giriş değişkenleri için MSE değerleri, sırasıyla eğitim, doğrulama ve test için 0.119 , 0.2091 ve 0.3313 olarak hesaplanmıştır. Test verileri için ölçülen ve edilen güneş radyasyonu verilerinin ( $\mathrm{t}$ zamanı için) rastgele seçilmiş olan günlere göre değişimi Şekil 5'te verilmiştir. Bu verilere göre bir gün önceki güneşlenme radyasyonu verilerini giriş değişkenlerine eklemek YSA yöntemin başarımını arttırmıştır. Koca ve ark. (2011) tarafından İran'da (Dezful) yapılan çalışmada, YSA modeline göre giriş değişkeni, günlük ortalama hava sıcaklığı, bağıl nem, güneşlenme süresi, rüzgar hızı ve buharlaşma değişkenleri ile güneşlenme radyasyonu yüksek başarım ile $(R=0.9957)$ ile elde edilmiştir. 

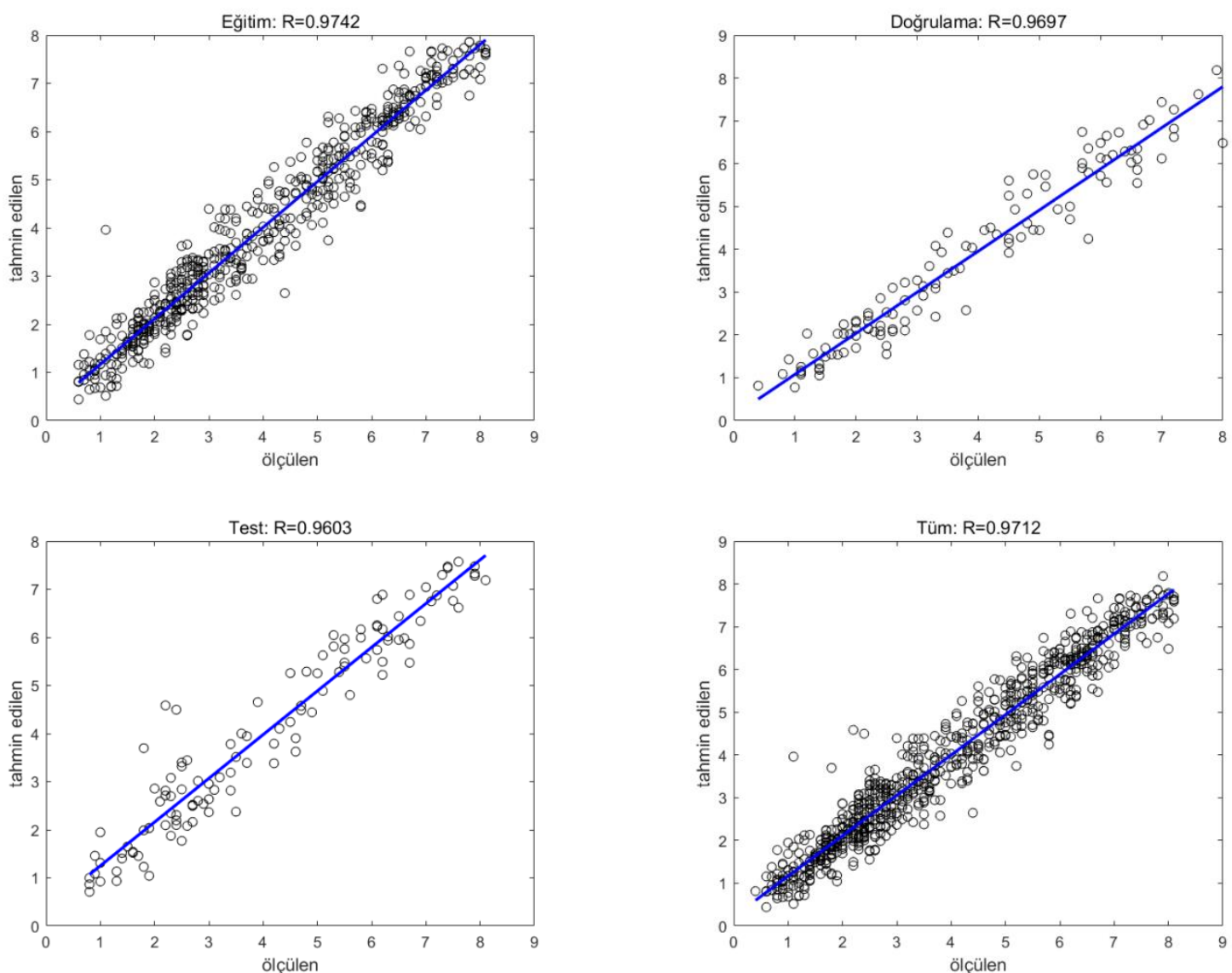

Şekil 3. Güneş radyasyonunun YSA eğitim, doğrulama, test ve tüm veri setleri için saçılma grafikleri

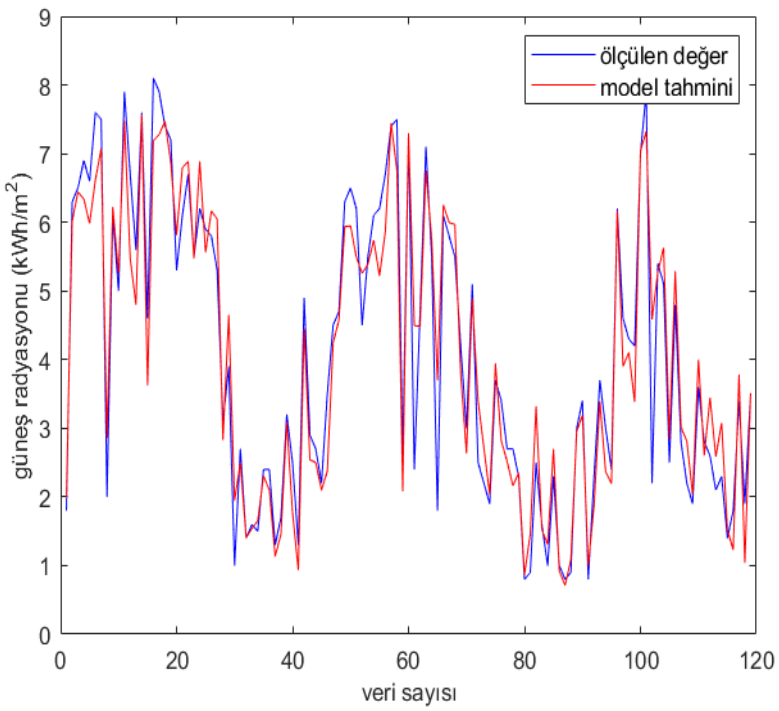

Şekil 4. Ölçülen ve YSA yöntemi ile tahmin edilen güneş radyasyonunun günlere göre dağıllımı (Girişler: $S, N N, R H, B B$, $B O, G S, E Y S, E D S, T S)$

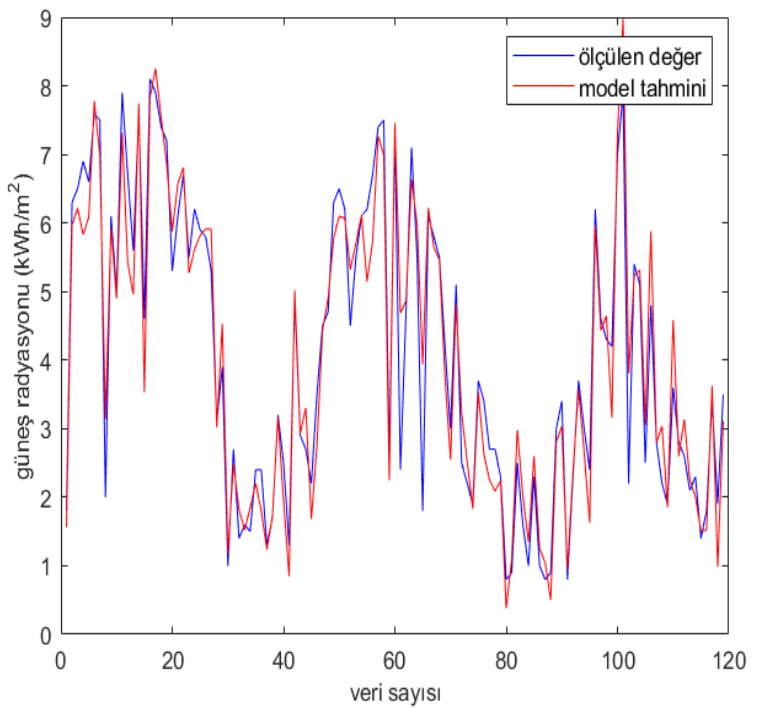

Şekil 5. Ölçülen ve YSA yöntemi ile tahmin edilen güneş radyasyonunun günlere göre dă̆ılımı (Girişler: $S, N N, R H, B B$, $B O, G S, E Y S, E D S, T S, G R(t-1))$ 


\section{Sonuçlar}

$\mathrm{Bu}$ çalışmada, meteorolojik veriler giriş değişkenleri olarak belirlenerek güneş radyasyonu YSA yöntemi ile tahmin edilmiştir. Test verileri için S, NN, RH, BB, BO, GS, EYS, EDS, TS değişkenlerinin ağa giriş olarak verildiği yapıda en yüksek korelasyon katsayısı $(\mathrm{R}=0.9603)$ elde edilmiştir. Yöntemin başarımı, girişteki meteorolojik değişkenler değiştirilerek de incelenmiştir. Burada, giriş değişkenlerinin azaltılmasına herbir meteorolojik değişkenin güneş radyasyonu ile korelasyonuna göre karar verilmiştir. Giriş değişkenleri azaltıldığında R değerleri de azalmaktadır. Sadece güneşlenme süresinin ağa giriş olarak verildiği yapıda $\mathrm{R}=0.9032$ elde edilmiştir ve farklı giriş değişkenleri (ve sayıları) için elde edilen en düşük korelasyon katsayısı olmuştur. İleri beslemeli YSA modeli yaklaşımının diğer meteorolojik değişkenler ile birlikte güneş radyasyonunu tahmin etmek için yüksek bir performans sağladığı (R 0.9032-0.9603) gözlemlenmiştir. Ayrıca, yöntemin bir gün önceki güneşlenme radyasyonu verileri $(\mathrm{GR}(\mathrm{t}-1))$ giriş değişkenlerine eklendiğinde, güneş radyasyonu $(\mathrm{GR}(\mathrm{t}))$ tahmininde başarımın $(\mathrm{R}=0.9625)$ arttığı görülmüştür.

\section{Teşekkür}

Bu çalışmada kullanılan Meteolorojik verilerin temin edilmesini sağlayan, Meteoroloji Genel Müdürlüğü’ne teşekkür ederiz.

\section{Kaynakça}

Alva, G., Lin, Y., Fang, G. (2018). An overview of thermal energy storage systems. Energy, 144, 341-378.

Amanollahi, J., Kaboodvandpour, S., Majidi, H., (2017). Evaluating the accuracy of ANN and LR models to estimate the water quality in Zarivar International Wetland, Iran. Natural Hazards, 85,1511-1527.

Atik, K., Deniz, E., Yıldız, E. (2007). Meteorolojik Verilerin Yapay Sinir Ağları ile Modellenmesi. KSÜ Fen ve Mühendislik Dergisi, 10 (1), 148-152.

Atkins, M.J., Walmsley, M.R.W., Morrison, A.S. (2010). Integration of solar thermal for improved energy efficiency in low-temperature-pinch industrial processes. Energy 35, 1867-1873.

Azadeh, A., Maghsoudi, A. and Sohrabkhani, S. (2009). An integrated artifcial neural networks approach for predicting global radiation. Energ. Convers. Manag. 50, 1497-1505.

Bayat, K. and Mirlatifi, S.M. (2009). Estimation of Global Solar Radiation using Regression and Artificial Neural Networks Models. Bimonthly Journal of Agricultural Sciences and Natural Resources, 16, 3, 270-280.

Behrang, M. A, Assareh, E., Ghanbarzadeh, A. and Noghrehabadi, A., (2010). The potential of different artiBcial neural network (ANN) techniques in daily global solar radiation modelling based on meteorological data. Sol. Energy 84; 1468-1480.

Bojanowski, J. S,. Donatelli, M., Skidmore, A. K. and Vrieling, A. (2013). An auto-calibration procedure for empirical solar radiation models; Environ. Model. Softw. 49, 118-128.

Changa, N.B., Daranpob, A., Yang, Y.J. and Jinc, K.R. (2009). Comparative Data Mining Analysis for Information Retrieval of MODIS Images: Monitoring Lake Turbidity Changes at Lake Okeechobee, Florida. Journal of Applied Remote Sensing, 3, 033549.
Culley, M.R., Carton, A.D., Weaver, S.R., Ogley-Oliver, E., StreetSun, J.C. (2011). Wind, Rock and Metal: Attitudes toward Renewable and Non-renewable Energy Sources in the Context of Climate Change and Current Energy Debates. Curr Psychol, 30, 215-233.

Gibb, D., Johnson, M., Romaní, J., Gasia, J., Cabeza, L.F., Seitz, A. (2018). Process integration of thermal energy storage systems - evaluation methodology and case studies. Applied Energy, 230, 750-760.

Heidari, E., Sobati, M.A., Movahedirad, S. (2016). Accurate prediction of nanofluid viscosity using a multilayer perceptron artificial neural network (MLP-ANN). Chemometrics and Intelligent Laboratory Systems, 155, 7385

IEA - International Energy Agency, (2018a). Key World energy statistics. Chemometrics and Intelligent Laboratory Systems 155 (2016) 73-85

IEA- International Energy Agency, (2018b). CO2 emissions from fuel combustion 2018 report.

Intergovernmental Panel on Climate Change. (2007). Climate change 2007: Synthesis report. New York: Cambridge University Press.

Koca, A., Oztop, H.F., Varol, Y., Koca, G.O. (2011). Estimation of solar radiation using artificial neural networks with different input parameters for Mediterranean region of Anatolia in Turkey. Expert Syst. Appl., 38, 8756-8762.

Koçak, B., Fernandez, A.I., Paksoy, H. (2020). Review on sensible thermal energy storage for industrial solar applications and sustainability aspects. Solar energy, 135169.

Kumar, S., Kaur, T., ve Arora, M. (2015). Estimationof Solar Radiation Using Artifical Neural Network. International Journal of Sciencen Technology \& Management, 4, 1, 658662.

Lee, J.S., Choi, H. (2019). Influence of Construction Schemes for a Non-compensatory Composite Indicator on Flood Vulnerability Assessments in the Korean Peninsula. International Journal of Civil Engineering, 1317-1325.

Moghadassi, A., Parvizian, F., Hosseini, S. (2009). A new approach based on artificial neural networks for prediction of high pressure vapor-liquid equilibrium Australian Journal of Basic and Applied Sciences, 3, 1851-1862.

Naderloo, L (2020). Prediction of solar radiation on the horizon using neural network methods, ANFIS and RSM (case study: Sarpol-e-Zahab Township, Iran). J. Earth Syst. Sci., 129, 148.

Oğuz, K. ve Pekin, M.A. (2019). Predictability of Fog Visibility with Artificial Neural Network for Esenboga Airport. European Journal of Science and Technology, 15, 542-551.

Oreskes, N. (2004). The scientific consensus on climate change. Science, 306, 1686-1686.

Özcan, C ve Köprü, E.Y. (2020). Yapay Sinir Ağları ile Sıv1 Ham Demir Tahmini ve 5.Yüksek Fırın Uygulaması. Avrupa Bilim ve Teknoloji Dergisi, Özel sayı, 155-162.

Strobl, R.O., Forte , F. (2007) Artificial neural network exploration of the influential factors in drainage network derivation. Hydrol Process 21(22):2965-2978.

Şahan, M., Okur, Y. (2016). Akdeniz bölgesine ait meteorolojik veriler kullanılarak yapay sinir ağları yardımıyla güneş 
enerjisinin tahmini. SDÜ Fen Edebiyat Fakültesi Fen Dergisi, 11,1 .

Turan, M., Dengiz, O., Turan, İ.D. (2018). Samsun İlinin Newhall Modeline Göre Toprak Sicaklık ve Nem Rejimlerinin Belirlenmesi. Türkiye Tarımsal Araştırmalar Dergisi , 5(2), 131-142.
UNEP (2015). Solar Heat for Industrial Processes.

Zhang, T., Liu, Y., Rao, Y., Li, X., Zhao, Q. (2020). Optimal design of building environment with hybrid genetic algorithm, artificial neural network, multivariate regression analysis and fuzzy logic controller. Building and Environment, 175, 106810. 